Please send trade news information and illustrations to Arveen Bajaj at the $B D J$, Nature Publishing Group, The Macmillan Building, 4-6 Crinan Street, London N1 9XW.

Trade news is provided as a service to readers using text and images from the manufacturer, supplier or distributor and does not imply endorsement by the $B D J$. Normal and prudent research should be exercised before purchase or use of any product mentioned.

\section{Happy visits}

Trycare have introduced an addition to its range of products designed to help relax children before treatment and motivate them afterwards.

The New Looney Tunes 'Maxivators' and 'Minivators' from Trycare Ltd feature many Looney Tunes characters including Bugs Bunny, Daffy Duck, Tweety Pie and the Road Runner.

The 'Maxivators' range also includes Tom \&t Jerry, Mr Men and Little Miss characters including Mr Chatterbox, Little Miss Sunshine, Little Miss Giggles and Mr Clever.

Supplied in rolls of 500 with two designs per roll, the range is larger than normal motivators, while each roll of the new 'Minivators' contains 2000 silver foil stickers with six different characters and the slogan 'Star Patient'.

Reader response number 50

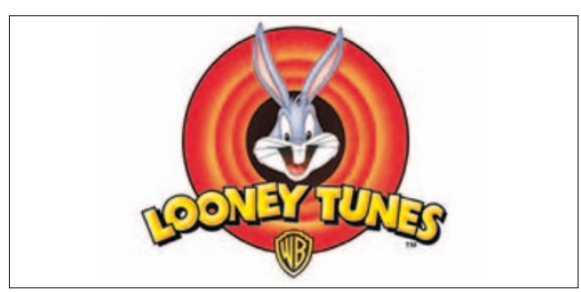

\section{Protective sealant}

Pro-seal is the new state of the art protective sealant from Reliance Orthodontic Products. It is the first sealant (chemical or light-cure) that will completely set without an oxygen inhibited layer. It creates a smooth, hard surface that ensures zero leakage, is extremely hydrophobic and makes paste clean up faster and easier.

A single liquid, Pro-seal is formulated to offer a number of significant benefits: it is highly filled to withstand toothbrush abrasion; it releases fluoride to help protect enamel; and it can be universally applied under any light cured, chemical cured, or dual-cured paste system.

Application of Pro-seal is simplified because it contains a fluorescing agent for easier monitoring of sealant coverage. It is available from Forestadent UK.

Reader response number 51

\title{
Early appointments
}

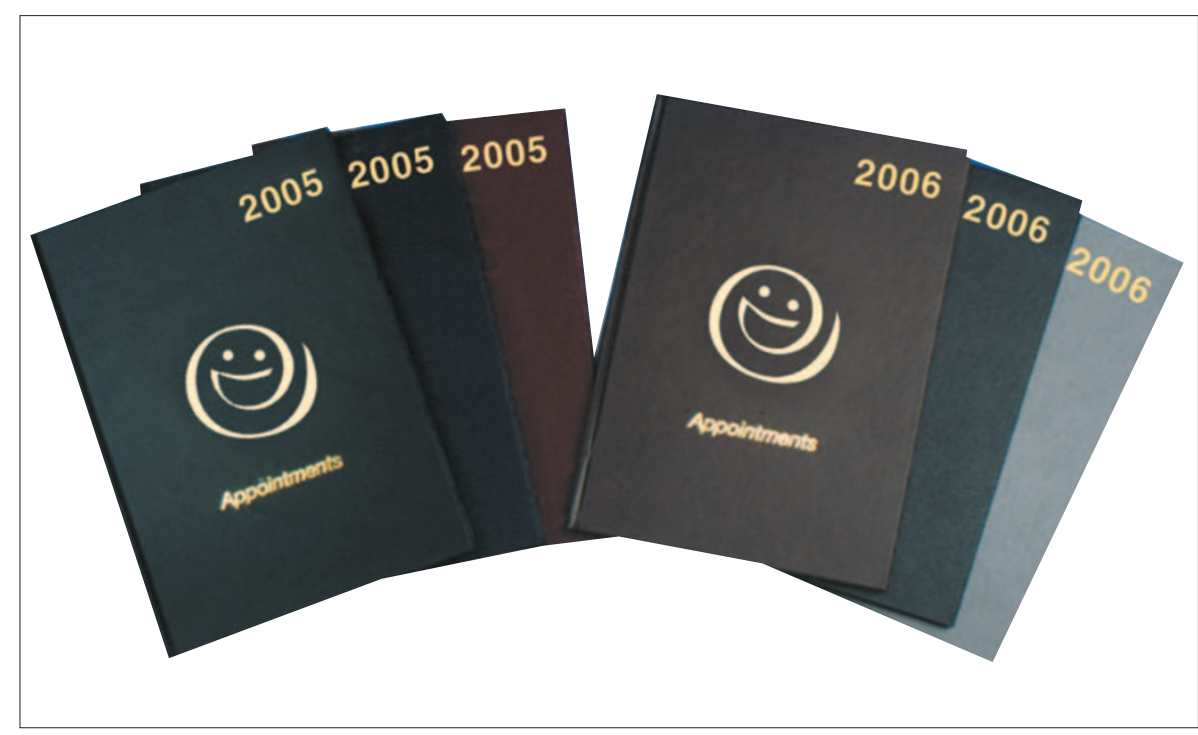

The British Dental Health Foundation has recently launched their 2006 Appointment Books.

The Foundation believes that the recent NICE recommendations mean that patients will now be booking appointments even further ahead making it likely the practice will be forward planning quite extensively.

The A4 hardbound books are strong and durable and come in a variety of colours black, blue, brown, green, grey or red. They allow for 15 minute appointments from $8 \mathrm{am}$ to $8 \mathrm{pm}$, Monday to Saturday. They also contain useful contact details for den-

\section{Easter surprise}

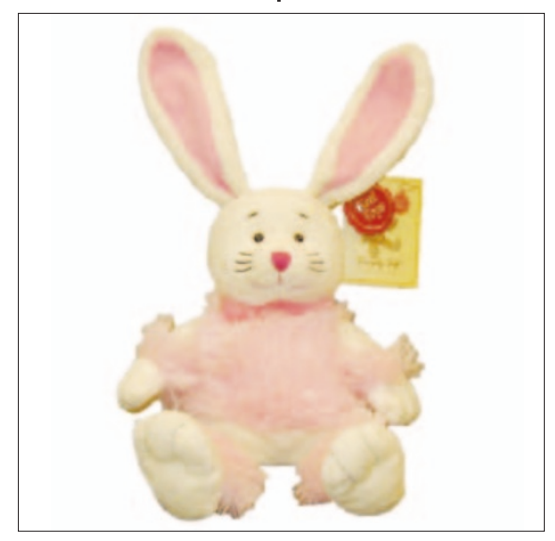

tal organisations and societies, space for advance appointments in 2007 and a useful address and notes section.

The Foundation still has a number of their 2005 appointment books in stock for those who require them. The books retail at $£ 14.34$ for members and £19.12 for nonmembers and prices exclude VAT and postage and packaging.

All money raised from the sale of resources goes towards maintaining the free information services provided by the Foundation.

Reader response number 52

Alkapharm is offering a free Keel Toy Wabbit Easter cuddly toy on purchase of selected products from its cleaning and disinfectant product range. These include any of the following: a Floor-Plus mop kit, one litre of Alkaspray-Plus spray, one litre of System-2 concentrate, one litre of ImpressiV trigger spray, one litre of System-4 concentrate, three tubs or three refill packs of Alkapharm Wipes or three tubs of Grande-Wipes. The offer is available while stocks last on purchases made before the 25th March 2005, through your usual dental wholesaler.

Reader response number 53 

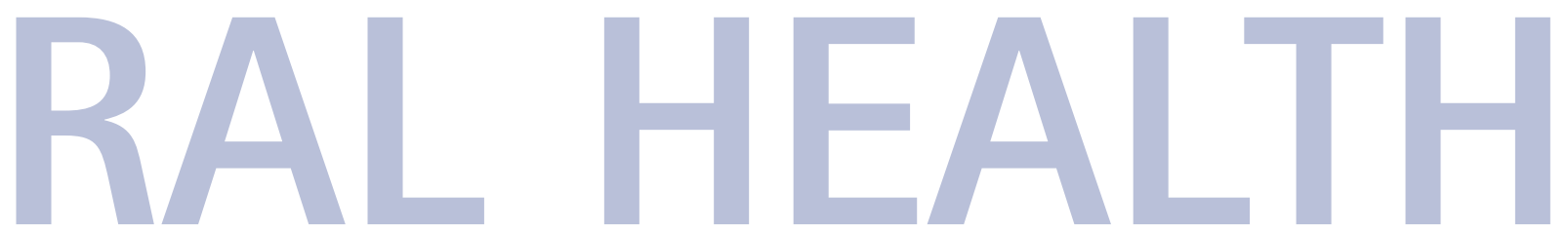
clean the vulnerable interdental spaces and keep them free of plaque.

Curaprox sensitive toothbrushes are manufactured with Curen bristles to offer a gentler alternative to standard toothbrushes and the CS Single Sulcular is a small toothbrush perfect for cleaning along the gum line and behind molars, accessing areas that standard toothbrushes cannot reach.

The new Curasept ADS mouthwash range has the advantages of a chlorhexidine mouthwash with the additional patient benefits of minimal oral discolouration, unpleasant changes in taste perception or alcohol. Curasept is also ideal for use both pre and post treatment.

Reader response number 54

\section{Search out plaque}

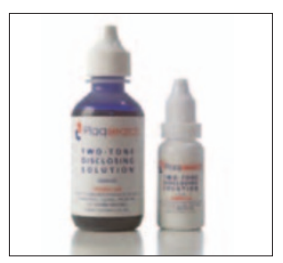

Plaqsearch is a solution from Oraldent which differentiates between old and new plaque by showing either blue or red staining after application. With red stains indicating recent plaque deposits and blue stains identifying older plaque, patients can see for themselves exactly where they need to take more care when cleaning.

The product has a pleasant minty flavour and stains fade quickly from the teeth, with no adverse reactions. It is used by painting it on the teeth with the cotton applicator or by placing 3-4 drops under the tongue, rinsing the mouth to remove excess solution and brushing teeth afterwards to thoroughly remove the stains.

Plaqsearch is offered in $60 \mathrm{ml}$ bottles for practice use and $15 \mathrm{ml}$ for home use.

\section{Oral irrigator}

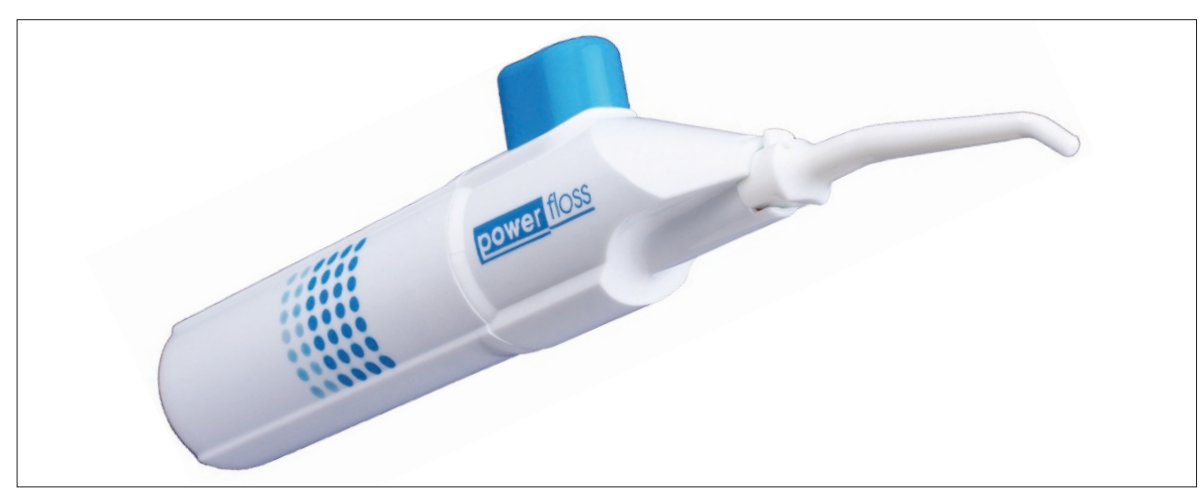

Patients can take better care of their teeth with the Powerfloss oral irrigator from Oraldent Ltd.

Suitable for all patients, including those with crowns, bridges, implants and braces, the Powerfloss oral irrigator is the ultimate oral irrigation tool for patients.

The product gently penetrates hidden and inaccessible areas and flushes out any lingering debris. Its unique, manual operat-

\section{Direct application}

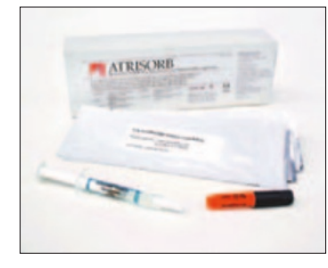

Atrisorb Direct is the reliable, direct application, guided tissue regeneration barrier from Oraldent. It isolates gingival connective tissues and prevents epithelial downgrowth into the intrabony defect, supporting the regeneration of the periodontal ligament and alveolar bone.

The unique, flowable barrier is customformed directly to the surgical site from a ed pump is ergonomically designed to allow the user to direct fluid at high pressure to all areas of the mouth, easily and with complete control.

Powerfloss helps to prevent tooth decay, gum disease and bad breath, is suitable for all patients, including those with braces, is portable and needs no batteries or electricity.

Reader response number 55

\section{Reducing hypersensitivity}

UnoDent De-Sen LC is the Dental Directory's own brand desensitiser.

Its light-curing, fluoride-releasing formula reduces hypersensitivity in most cases after just one application. Furthermore, De-Sen LC has the additional benefit of protecting teeth against external influences and abrasion.

Reader response number 58

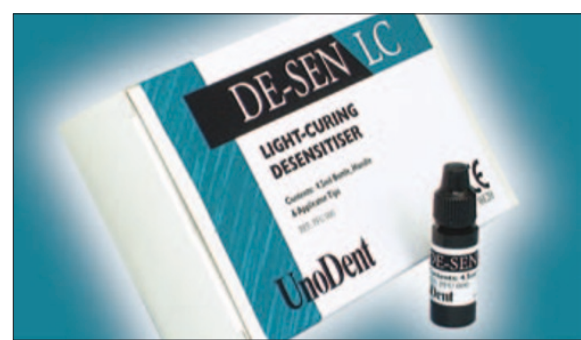

free flow, polymer formulation gel which hardens into a biodegradable, semi-solid barrier when sprayed with sterile water or saline.

The product adapts to cover every defect of the post operative bone graft being treated, creating an intimate contact between the barrier and the root surface. It is ultimately completely absorbed, eliminating the need for repeat surgery to remove a barrier, but retains its structural mass for at least 20 weeks after placement.

Reader response number 57 


\section{Oral hygiene essentials}

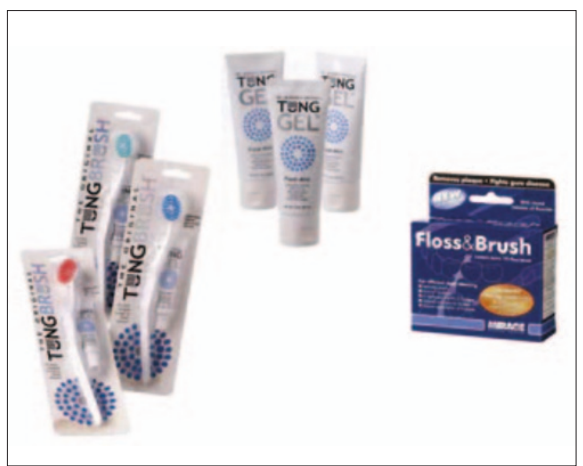

Mirage Dental has created a unique mix of professional and patient-led oral hygiene essentials, three of which are items particularly focussing on bettering the breath.

The Floss \& Brush is an ergonomically designed interdental brush for cleansing the mouth for use at home or on the move. They appeal to the large number of patients who

\section{Sonic technology}

Henry Schein had added the Philips Sonicare range of toothbrushes to its range of oral healthcare products, including the Sonicare Elite.

The next generation brush and head design offers exceptional cleaning, comfort and ease-of-use.

It combines patented sonic technology with advanced design, creates a high speed bristle motion and a dynamic, fluid, cleaning action which results in improved interproximal cleaning. It features a Smartimer, easy-start brushing power ramp-up, extra gentle bristle design, ergonomic tapered handle and dual colour recharge indicator. Reader response number 60

\section{Teaching made simple}

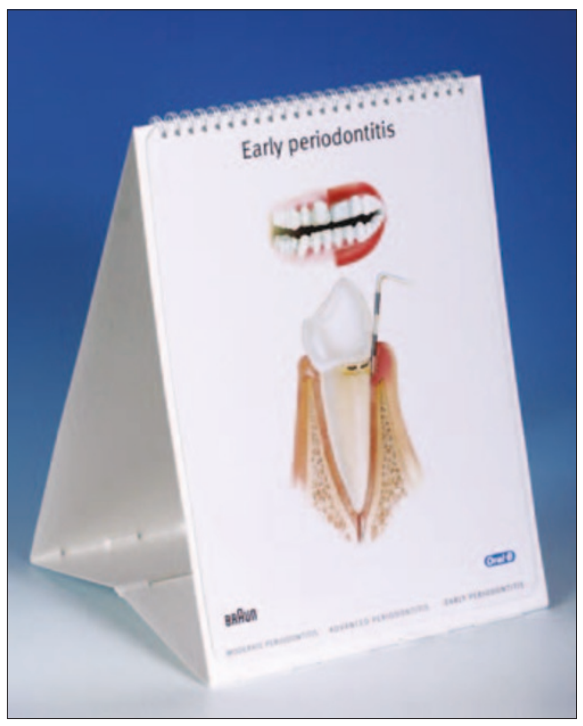

find flossing the traditional way tiresome and are particularly appropriate for patients with appliances as they are built to manoeuvre around them.

Each brush contains $0.25 \mathrm{mg}$ of fluoride, which gradually dissolves when it comes into contact with saliva to strengthen the enamel.

The Original TungBrush brushes the tongue clean. Developed by a dentist, it features a large round head and short, firm bristles that gently and effectively remove debris lodged in the tongue where the longer filaments of a toothbrush would bend flat against the tongue's pitted surface.

Lastly the Original TungGel can be used with the TungBrush and cleans and freshens for hours. The minty, zinc-based gel is highly water-soluble so there is no build-up and it rinses clean away.

Reader response number 59

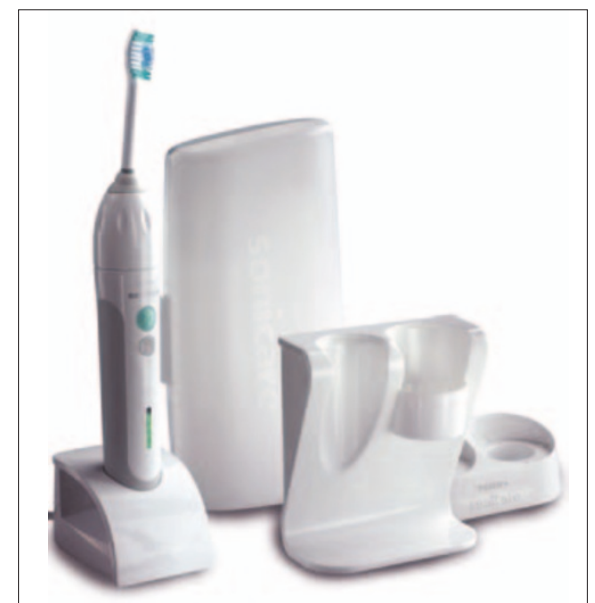

Oral-B has produced a high-quality 'Atlas' that will help dentists and hygienists demonstrate cleaning techniques and explain the causes and symptoms of dental disease in order to help improve an individual's oral hygiene. It includes illustrations of the various stages of periodontal disease and dental decay and also contains pictures to demonstrate correct brushing techniques.

The product is designed to help patients who though are sufficiently motivated to clean their teeth, might benefit from improving their technique to ensure that the job is done well.

If you would like an Atlas for your practice please contact your local representative or call Oral-B direct on 02088477817. Reader response number 61 